\title{
Isolation and Study of an Acquired Inhibitor of Human Coagulation Factor $\mathbf{V}$
}

\author{
Michael E. Nesheim, William L. Nichols, Therese L. Cole, Jessie G. Houston, \\ Richard B. Schenk, Kenneth G. Mann, and E. J. Walter Bowie \\ Hematology Research Section and the Special Coagulation Laboratory, Division of Hematology and Internal Medicine, \\ Mayo Clinic/Foundation, Rochester, Minnesota 55905; Departments of Medicine and Biochemistry, Queen's University, Kingston, \\ Ontario, Canada K7L-3N6; Department of Internal Medicine and Department of Pathology, Carle Clinic, Urbana, Illinois 61801
}

\begin{abstract}
A coagulation Factor $V$ inhibitor developed in a man 75 yr of age in association with an anaplastic malignancy and drug treatment (including the aminoglycoside antibiotic, gentamicin). The patient did not bleed abnormally, despite both surgical challenge and plasma Factor $V$ activity of $<1 \%$. The inhibited plasma had grossly prolonged prothrombin and activated partial thromboplastin times, but a normal thrombin time. Mixing studies indicated progressive coagulation inhibition with normal plasma, but not with Factor V-deficient plasma, and reversal of coagulation inhibition by the addition of bovine Factor $V$ to the patient's plasma. $1 \mathrm{ml}$ of patient plasma inhibited the Factor $V$ activity of $90 \mathrm{ml}$ of normal human plasma. The inhibitor was isolated by sequential affinity chromatography on protein A-Sepharose and Factor V-Sepharose. The IgG isolate markedly inhibits the activity of prothrombinase assembled from purified Factors $\mathrm{Xa}$ and Va, calcium ion, and phospholipid vesicles, and partially inhibits prothrombinase assembled from purified Factor $\mathbf{X a}$, calcium ion, and normal platelets. The Factor $\mathbf{V}$ of platelets, however, appears relatively inaccessible to the antibody, inasmuch as platelets isolated from whole blood supplemented for $8 \mathrm{~h}$ with the antibody functioned normally with respect to platelet Factor V-mediated prothrombinase function. The absence of obvious hemorrhagic difficulties in the patient, the total inhibition of plasma Factor $\mathbf{V}$ by the inhibitor, and the apparent inaccessibility of platelet Factor $V$ to the inhibitor specifically implicate platelet Factor $\mathrm{V}$ in the maintenance of hemostasis.
\end{abstract}

\section{Introduction}

Coagulation Factor $\mathrm{V}$ is a high molecular weight $(330,000)$ singlechain glycoprotein that circulates in human plasma at a level of $\sim 7 \mu \mathrm{g} / \mathrm{ml}(1-3)$. It is the precursor of Factor Va, a two-subunit protein that is produced by limited proteolysis of Factor V. Factor $\mathrm{Va}$ functions as an essential cofactor in the Factor Xa-catalyzed activation of the vitamin K-dependent zymogen, prothrombin, to the blood-clotting enzyme, thrombin. The reaction is catalyzed by the prothrombinase complex, which is composed of a molecule each of Factor Xa and Factor Va, a cellular (platelet) or

This work was presented in part at the Sixth National Thrombosis Conference, American Heart Association, Miami, FL, November 1984, and was published as an abstract (1984. Circulation. 70(Part 2):II-199).

Address reprint requests to Dr. Nesheim, Department of Medicine, Queen's University, Kingston, Ontario, Canada K7L 3N6.

Received for publication 1 February 1985 and in revised form 29 August 1985.

J. Clin. Invest.

(c) The American Society for Clinical Investigation, Inc.

$0021-9738 / 86 / 02 / 0405 / 11 \$ 1.00$

Volume 77, February 1986, 405-415 phospholipid surface, and calcium ion (4-10). Factor Va functions in the complex both by providing the equivalent of a receptor for Factor $\mathrm{Xa}$ and by enhancing, by an approximate factor of 3,000, the turnover number characterizing prothrombin activation $(8,9,11,12)$. Although Factor $\mathrm{Va}$ has no known enzymatic properties of its own, its participation in prothrombin activation increases the rate of the process by four to five orders of magnitude under conditions that might typify those in vivo $(7,9)$. Thus, studies of the reaction in vitro suggest that Factor $\mathrm{Va}$ is essential for normal hemostasis.

Approximately $80 \%$ of the Factor $\mathrm{V}$ of human whole blood is plasmatic, whereas $\sim 20 \%$ is associated with platelets (3). Thus, in blood two distinct pools of the cofactor exist. The relative contributions, however, of plasmatic and platelet Factor $\mathrm{V}$ to the hemostatic process are not clearly defined.

Both congenital deficiencies and spontaneously occurring inhibitors of human Factor $\mathrm{V}$ have been reported, although their recognized occurrence is rare (13-43). Spontaneously occurring inhibitors have proven to be antibodies that, in most instances, have occurred acutely in individuals who had been otherwise apparently normal with respect to hemostasis. The existence of Factor $\mathrm{V}$ inhibitors has typically been of short duration. No obvious common etiology for the occurrence of these inhibitors can be found among the cases reported to date, although in many instances (including the present one) they have been associated with the administration of aminoglycoside antibiotics (e.g., streptomycin, gentamicin, or kanamycin).

Although most individuals with severe congenital Factor $\mathbf{V}$ deficiency have had abnormal bleeding, bleeding tendencies in individuals with spontaneously occurring inhibitors of Factor $\mathrm{V}$ have been very variable. In some instances, bleeding has been severe, even fatal. In others, bleeding symptoms have ranged from mild to absent, even though inhibitors were present at sufficiently high titers to produce clotting abnormalities in vitro that would suggest life-threatening defects. Taken together, these observations have not provided an unequivocal assessment of whether Factor $\mathbf{V}$ is essential for normal hemostasis in vivo. Previously reported studies of patients with acquired Factor $\mathrm{V}$ inhibitors, however, have not differentiated the extent of functional deficiencies in both the plasma and the platelet Factor $\mathrm{V}$ pools.

Recently, Tracy et al. (44) reported studies of a family, several members of which exhibited near-normal levels of Factor $\mathrm{V}$ antigen in both plasma and platelets, and had functionally normal plasma Factor V, but grossly abnormal platelet Factor $\mathrm{V}$ function. Associated with these characteristics was a profound bleeding tendency. These studies suggest an essential role for platelet Factor $\mathrm{V}$ in normal hemostasis. The hemostatic importance of platelet Factor $\mathrm{V}$ is also suggested by the experience of Chediak et al. (30), who were able to manage successfully a bleeding diathesis associated with a Factor $\mathrm{V}$ inhibitor by transfusion of platelets, whereas transfusion of fresh-frozen plasma was inef- 
fective. Miletich et al. (42), in studies of Factor Xa binding and prothrombinase activity expressed by platelets isolated from patients with Factor $\mathrm{V}$ deficiencies, found that the severity of clinical bleeding correlated better with decreased Factor Xa-platelet binding (presumably to Factor $\mathrm{Va}$ ) and decreased platelet prothrombinase activity than with plasma Factor V levels. Studies reported in 1961 by Borchgrevink and Owren (45) suggest that, in congenital Factor $\mathrm{V}$ deficiency, transfusion of normal platelets might achieve hemostatic improvement for several days (as assessed by rebleeding from skin wounds) as contrasted with the more transient improvement of plasma Factor $\mathrm{V}$ activity. These several studies thus suggest that the Factor $\mathrm{V}$ of human platelets may be essential to hemostasis.

The present studies were undertaken to characterize a spontaneously occurring inhibitor of Factor $V$ that developed in a patient who displayed no obvious bleeding problems. Initial studies indicated that the plasma Factor $\mathrm{V}$ of this individual was profoundly inhibited, but the state of his platelet Factor $\mathrm{V}$ was unknown. Efforts were undertaken to isolate and further characterize the inhibitor, and to study its influence on plasma and platelet Factor V. This manuscript constitutes a report of these studies.

\section{Case report}

A 75-year-old man, previously in good health, became ill in January 1984. His symptoms included fever, weight loss, and pleuritic chest pain. In mid-February 1984 he was admitted to his local hospital. Chest $x$-rays suggested an infiltrate in the left lower lung, and treatment with antibiotics (gentamicin and carbenicillin) was begun. Because his condition did not improve, he was transferred to the Carle Clinic where he was hospitalized from 20 February through 11 March.

Fig. 1 illustrates the principal clinical and laboratory events subsequently associated with the patient's illness. At admission the patient was febrile $\left(40^{\circ} \mathrm{C}\right)$. Chest $\mathrm{x}$-rays revealed bilateral small pleural effusions, more prominent on the left, and a small area of infiltration or consolidation laterally in the left lower lung. Left thoracentesis and pleural needle biopsy were performed, uneventfully; chemical, microbiologic, cytologic, and histologic analysis of these materials did not yield a specific diagnosis. A lung radioisotope scan suggested possible pulmonary embolism. The patient was treated with intravenous heparin, and antibiotic treatment was reestablished (gentamicin and cefamandole). Other medications administered at this time included digoxin and furosemide. Body scanning after intravenous administration of gallium-67 revealed abnormal radioisotope uptake in the right axilla and in the left pelvic area. Physical examination at this time confirmed a 3-cm mass in the right axilla and a palpable mass in the left iliac fossa. On 1 March heparin therapy was stopped, and on 2 March the patient underwent transabdominal open surgical biopsy through a 6-inch muscle-splitting incision in the left lower abdomen. A large nodular tumor mass was encountered, and this was partially resected. The patient experienced no abnormal bleeding at the operative site, either intraoperatively or postoperatively. He did not previously nor subsequently experience any abnormal bleeding, either "spontaneously" or with trauma (e.g., bruising, hematomas, epistaxis, etc.).

Postoperatively, it was discovered that the patient's prothrombin time and activated partial thromboplastin time were remarkably prolonged, despite previous cessation of heparin therapy (Fig. 1). Mixing studies with normal plasma suggested

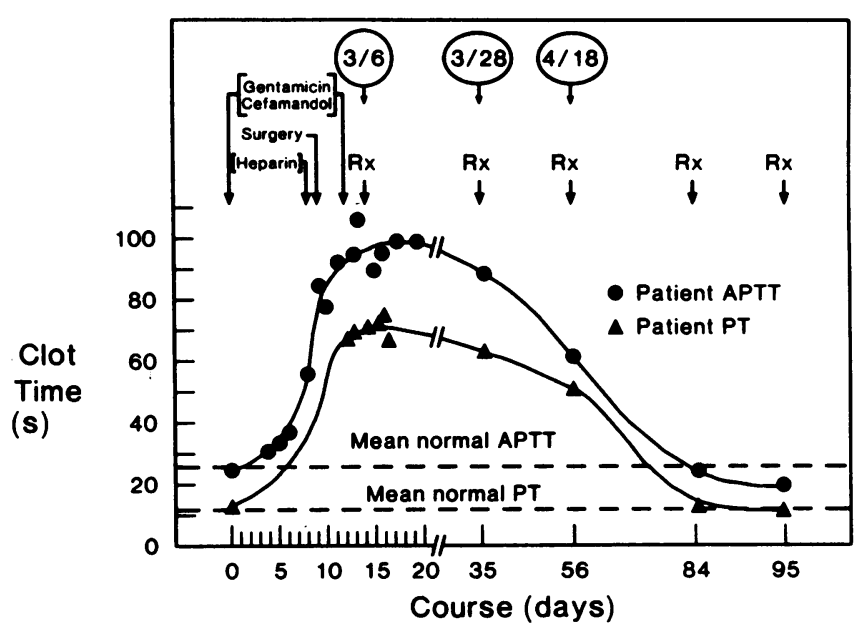

Figure 1. Temporal course of the patient's Factor $\mathrm{V}$ inhibitor, and associated clinical events. Day 0 on the abscissa represents the first day of hospitalization, 22 February. During the course of drug administration (heparin, day 0 to day 8; gentamicin and cefamandole, day 0 to day 12 ) the prothrombin time $(P T)$ and activated partial thromboplastin time $(A P T T)$ of the patient's plasma became markedly prolonged (coagulation tests performed at Carle Clinic). The prolongation of the clot times persisted after cessation of heparin administration. Despite surgical challenge (transabdominal open biopsy of retroperitoneal malignancy, day 9), in the presence of marked prolongation of the clot times, the patient did not bleed abnormally. Chemotherapy $(R x)$ of the patient's disseminated malignancy was administered on the days indicated (prednisone, cyclophosphamide, doxorubicin). The patient's coagulation inhibitor was of transient duration $(\sim 11 \mathrm{wk})$. Samples of the patient's plasma were obtained on the dates encircled $(3 / 6,3 / 28$, $4 / 18$ ) and were subjected to additional study at Mayo Clinic.

the presence of a coagulation inhibitor. A frozen sample of the patient's citrate-anticoagulated plasma (platelet-poor), obtained 6 March, was referred to the Special Coagulation Laboratory (Mayo Clinic) for further study. Additional samples of the patient's plasma were obtained and frozen on 28 March and on 18 April. Informed consent for blood sampling and study was obtained from the patient and from the normal blood donors employed (Drs. Nesheim and Nichols).

Histologic examination of the patient's tissue biopsy revealed lymph node tissue replaced by sheets of extremely anaplastic cells. The biopsy specimen was reviewed by pathologists at the Carle Clinic and at the Mayo Clinic, and, although clearly indicative of a malignant process, could not be definitely classified either as carcinoma or as lymphoma, despite additional study by electron micrography and by indirect immunoperoxidase staining for immunoglobulin light chains. Immunoelectrophoresis of the patient's serum, using heterologous antisera specific for human IgG, IgA, IgM, and $\kappa$ - and $\lambda$-light chains, did not reveal any detectable monoclonal immunoglobulin. Immunodiffusion of the patient's serum, using antisera to IgD and IgE, was not remarkable. Immunofixation of the electrophoretically separated serum proteins with IgG and $\kappa$ and $\lambda$ antisera showed no localized protein bands.

Postoperatively, computed tomographic radiography of the abdomen confirmed a residual nodal mass in the left iliac fossa, and also revealed abnormal small para-aortic lymph nodes. On 7 March the patient began treatment with oral prednisone and with intravenous cyclophosphamide and doxorubicin. Similar 
treatments were administered intermittently as indicated in Fig. 1. During the course of these treatments, the patient's axillary adenopathy neither regressed nor enlarged; however, computed tomographic radiography of the abdomen on 16 May showed a marked decrease in the size of the left iliac fossa mass. The patient's prothrombin time was normal at this time and remained so. Near the end of June, pain in the lower abdomen and swelling of the left leg supervened. Relapse of malignancy was thought likely, but the patient refused further investigation and treatment, other than palliative measures. Subsequently, he developed scrotal and bilateral leg edema, as well as renal failure, in association with marked increases in palpable adenopathy in the left iliac fossa and in the right axilla. The patient died 22 August 1984. Autopsy examination was not performed.

\section{Methods}

\section{Materials}

$\mathrm{CH}$ Sepharose, activated with $\mathrm{N}$-hydroxysuccinimide, and protein ASepharose were obtained from Sigma Chemical Co., St. Louis, MO. Human prothrombin, Factor $\mathrm{X}$, and Factor $\mathrm{V}$ were prepared as described previously $(2,46)$. Bovine Factor $V$ was isolated according to the procedure of Nesheim et al. (2). Factor X was activated to Factor Xa with the activator from Russell's viper venom immobilized on Sepharose (7). Human Factor V-deficient plasma was prepared by removing Factor $\mathbf{V}$ with an immobilized anti-Factor $\mathrm{V}$ monoclonal antibody (2). Vesicles of phospholipid (phosphatidylserine-phosphatidylcholine, 1:3 wt/wt) were prepared as described by Barenholz et al. (47). The fluorescent, reversible thrombin inhibitor, dansylarginine- $N$ (3-ethyl-1,5-pentanediyl)amide (DAPA), ${ }^{1}$ was prepared as described by Nesheim et al. (48). Rabbit brain thromboplastin used in coagulation assays was prepared as described $(2,49)$. All other reagents were of analytical quality.

\section{Methods}

Clotting assays. Detection and assay of the inhibitor were based on the ability of the inhibitor to prolong the prothrombin time of normal human plasma. Prothrombin time measurements typically were performed by adding in succession to a $13 \times 85 \mathrm{~mm}$ glass tube fresh normal citrated human plasma $(50 \mu \mathrm{l})$, and the sample $(50 \mu \mathrm{l})$ containing the inhibitor. These were incubated $2 \mathrm{~min}$ at $37^{\circ} \mathrm{C}$. Thromboplastin was then added $(50 \mu \mathrm{l})$, and clotting was initiated at $37^{\circ} \mathrm{C}$ with the addition of an aliquot $(50 \mu \mathrm{l})$ of $0.025 \mathrm{M} \mathrm{CaCl}_{2}$. The tube was rocked back and forth in a $37^{\circ} \mathrm{C}$ water bath and the time to clot formation, detected visually, was measured. Standard clotting assays for Factors II, V, VII, VIII, and X were performed as described previously (49) using the appropriate factor-deficient plasmas.

Human Factor V-Sepharose was prepared by stirring human Factor $\mathrm{V}\left(3.5 \mathrm{mg}\right.$ in $35 \mathrm{ml}$ of $0.1 \mathrm{M} \mathrm{NaHCO}_{3}, 0.2 \mathrm{M} \mathrm{NaCl}, \mathrm{pH} 8.5$ ) with 4.0 $\mathrm{ml}$ of $\mathrm{CH}$-Sepharose (activated with $\mathrm{N}$-hydroxysuccinimide) at $22^{\circ} \mathrm{C}$. After $1 \mathrm{~h}, 1 \mathrm{M}$ Tris $\cdot \mathrm{HCl}, \mathrm{pH} 8.0(10 \mathrm{ml})$ was added, and stirring was continued at $4^{\circ} \mathrm{C}$ overnight. The slurry was poured into a plastic column (12- $\mathrm{cm}^{3}$ disposable syringe with porous polyethylene frit) and washed with $0.02 \mathrm{M}$ Tris $\cdot \mathrm{HCl}, 0.15 \mathrm{M} \mathrm{NaCl}, \mathrm{pH}$ 7.4. The coupling efficiency, determined by intrinsic fluorescence $(\lambda e x=280, \lambda e m=340$ ), was $\sim 90 \%$.

Isolation of the Factor V inhibitor. Plasma ( $2.0 \mathrm{ml}, 28 \mathrm{March}$ sample) containing the inhibitor was applied at $22^{\circ} \mathrm{C}$ to a $3.5-\mathrm{ml}$ column of protein A-Sepharose equilibrated in $0.1 \mathrm{M}$ sodium phosphate $(0.05 \%$ $\mathrm{NaN}_{3}$ ), pH 8.0. Flow was interrupted for $0.5 \mathrm{~h}$ and then recommenced with the same buffer. Washing was continued with $0.1 \mathrm{M}$ sodium citrate $\left(0.05 \% \mathrm{NaN}_{3}\right), \mathrm{pH} 6.0$. The inhibitor was then eluted in the antibody fraction using $0.1 \mathrm{M}$ sodium citrate $\left(0.05 \% \mathrm{NaN}_{3}\right), \mathrm{pH} 3.0$. The flow rate was $\sim 0.5 \mathrm{ml} / \mathrm{min}$, and fractions of $2.0 \mathrm{ml}$ were collected into 0.6 $\mathrm{ml}$ of $1 \mathrm{M}$ Tris $\cdot \mathrm{HCl}, \mathrm{pH}$ 8.0. The inhibitory activity was monitored by

1. Abbreviations used in this paper: ACD, acid-citrate dextrose; DAPA, dansylarginine- $N$ (3-ethyl-1,5-pentanediyl)amide. clotting assays, performed by incubating an appropriately diluted sample $(50 \mu \mathrm{l})$ plus an aliquot $(50 \mu \mathrm{l})$ of a mixture of human Factor V-deficient plasma and normal human plasma (9:1) for $2 \mathrm{~min}$ at $22^{\circ} \mathrm{C}$. An aliquot of thromboplastin $(50 \mu \mathrm{l})$ was added, and after a brief incubation at $37^{\circ} \mathrm{C}$, the prothrombin time of the sample was measured after initiation of clotting with an aliquot $(50 \mu \mathrm{l})$ of $0.025 \mathrm{M} \mathrm{CaCl}_{2}$. The relationship between inhibitor concentration and clotting time was established with serial dilutions of the starting plasma, the inhibitor content of which was defined as $100 \mathrm{U} / \mathrm{ml}$ (this value was chosen because neutralization studies had indicated that the inhibitor present in $1 \mathrm{ml}$ of patient plasma would neutralize the Factor $\mathrm{V}$ of $\sim 100 \mathrm{ml}$ of normal human plasma, which by conventional definition has a Factor $V$ content of $1 \mathrm{U} / \mathrm{ml}$ ). Factor $V$ antigen levels in the starting plasma and in the fractions obtained upon chromatography with protein A-Sepharose were determined by radioimmunoassay as described previously (3). The fractions with inhibitor activity were pooled, dialyzed against $0.02 \mathrm{M}$ Tris $\cdot \mathrm{HCl}, 0.15 \mathrm{M} \mathrm{NaCl}, \mathrm{pH}$ 7.4, and applied to a column of human Factor V-Sepharose equilibrated at $22^{\circ} \mathrm{C}$ in the same buffer. The flow rate was $\sim 0.5 \mathrm{ml} / \mathrm{min}$, and fractions of $4.0 \mathrm{ml}$ were collected. The column was washed with the same buffer, and the inhibitor was eluted with $0.1 \mathrm{M}$ glycine, $0.5 \mathrm{M} \mathrm{NaCl}, \mathrm{pH} 2.8$. The eluate of low $\mathrm{pH}(\sim 2.0 \mathrm{ml} /$ fraction $)$ was collected into tubes containing $0.3 \mathrm{ml} 1 \mathrm{M}$ Tris $\cdot \mathrm{HCl}, \mathrm{pH} 8.0$, in order to avoid prolonged exposure to low $\mathrm{pH}$ conditions. The absorbance $(A, 280 \mathrm{~nm})$ and inhibitor activity of the fractions were then determined.

Electrophoretic analysis. The material of the fractions obtained at pH 3.0 from protein A-Sepharose and pH 2.8 from human Factor VSepharose was analyzed by polyacrylamide slab gel electrophoresis (5$15 \%$ acrylamide gradient) in the presence of sodium dodecyl sulfate, using the alkaline discontinuous buffer system as described by Neville (50) except that the lower electrode buffer consisted of $0.04 \mathrm{M}$ Tris $\cdot$ borate, pH 8.6.

Measurement of immunoglobulin inhibitory activity in purified systems of prothrombinase assembled on phosphatidylcholine-phosphatidylserine vesicles or on washed human platelets. Human platelets were isolated from citrated whole blood by the method of Mustard et al. (51), as modified by Tracy et al. (44), and were maintained at $37^{\circ} \mathrm{C}$ in siliconized glass tubes as stock suspensions of $1.2 \times 10^{9}$ platelets $/ \mathrm{ml}$ in Tyrode's buffer supplemented with $10 \mathrm{mM}$ Hepes, $\mathrm{pH}$ 7.4. For fluorometric assay of prothrombinase, platelets were suspended in plastic fluorometer cuvettes such that the final compositions of the contents (1.5 $\mathrm{ml}$ ) of the cuvettes were: platelets, $3.6 \times 10^{8} / \mathrm{ml}$; prothrombin, $1.39 \mu \mathrm{M}$; $\mathrm{Ca}^{2+}, 2.5 \mathrm{mM}$; DAPA, $3.0 \mu \mathrm{M} ; \mathrm{pH} 7.4 ; 22^{\circ} \mathrm{C}$; and various concentrations of the inhibitor isolated by protein A-Sepharose chromatography. At this platelet concentration, the total platelet Factor $\mathrm{V}$ concentration was about $1.3 \mathrm{nM}$, based on 5,000 molecules per platelet (3). Conversion of prothrombin to thrombin was initiated with an aliquot of human Factor $\mathrm{Xa}$ (10 nM, final concentration). The progress of the reaction was monitored by the fluorescence intensity of the DAPA-thrombin complex (7). Fluorescence measurements were performed with a Perkin Elmer MPF44A spectrofluorometer (Perkin-Elmer Corp., Instrument Div., Norwalk, CT) using excitation and emission wavelengths of 335 and $565 \mathrm{~nm}$, respectively. A 430-nm cutoff filter was used on the emission beam. The rate of thrombin formation was measured from the initial slopes of profiles of fluorescence intensity versus time. Similar experiments were performed with phosphatidylcholine-phosphatidylserine vesicles plus isolated, thrombin-activated human Factor $V$ in place of the platelets. The final concentrations of the phospholipid and Factor Va were $20 \mu \mathrm{M}$ and $1.0 \mathrm{nM}$, respectively.

Incubation of normal human platelets with control or patient immunoglobulins. The IgG fraction from either $35 \mathrm{ml}$ of normal plasma or $35 \mathrm{ml}$ of the patient's plasma (18 April sample) was isolated by chromatography on protein A-Sepharose $(8.0 \mathrm{ml}$, capacity $25 \mathrm{mg} \mathrm{IgG/ml).}$ After the IgG had been eluted ( $\mathrm{pH} 3.0$ ) from the column, the sample was reapplied, and the elution step was repeated to assure complete removal of the antibody fraction. The IgG from the two steps was combined and precipitated with ammonium sulfate (75\% saturation). The suspension was centrifuged at $15,000 \mathrm{~g}, 4^{\circ} \mathrm{C}, 20 \mathrm{~min}$, and the pellets were dissolved in a minimal volume of $0.15 \mathrm{M} \mathrm{NaCl}$ and dialyzed against 
ACD (acid-citrate dextrose) anticoagulant solution. The volume after dialysis was adjusted to $12 \mathrm{ml}$ with ACD. The solutions of normal or patient IgG in ACD were then used as anticoagulants for $80-\mathrm{ml}$ aliquots of whole blood. The anticoagulated blood samples were incubated at $37^{\circ} \mathrm{C}$, aliquots were removed after 1 and $8 \mathrm{~h}$, and the platelets of the specimens were isolated according to the method of Mustard et al. (51), as modified by Tracy et al. (44). The platelets were suspended at 1.2 $\times 10^{9} / \mathrm{ml}$. Aliquots $(0.3 \mathrm{ml})$ were either activated with thrombin $(1.0$ $\mathrm{U} / \mathrm{ml}, 2 \mathrm{~min}, 22^{\circ} \mathrm{C}$ ) or were not stimulated, and the activity of the platelets to provide Factor $\mathrm{Va}$ and the catalytic surface of prothrombinase was determined fluorometrically by measurements of the rate of prothrombin activation and thrombin generation. These measurements were performed as described above.

\section{Results}

Properties of the inhibitor as determined by clotting assays. The inhibitor was initially detected by virtue of its ability to prolong the clotting times of standard clotting assays. The coagulation test profile is listed in Table I. These data indicated a markedly prolonged prothrombin time and activated partial thromboplastin time, and a nearly normal thrombin time. The results obtained from the platelet neutralization procedure (52) suggested that the patient's inhibitor was not a "lupus anticoagulant." Assays for coagulation Factors II, VII, VIII, and X were inhibited as evidenced by higher apparent values upon dilution of the samples. Of those factors assayed, Factor $\mathrm{V}$ levels were the lowest, suggesting the possibility of a Factor $\mathrm{V}$ inhibitor. After passage of the plasma sample through protein A-Sepharose, assays for Factors II, VII, and X were not inhibited and yielded normal values. This procedure, however, did not restore Factor $\mathrm{V}$ activity.

As a test of the hypothesis that the inhibitor was directed against Factor V, its time course of inhibition was determined in normal or Factor V-deficient plasma. An aliquot $(2.5 \mu \mathrm{l})$ of

Table I. Coagulation Test and Factor Assay Results Obtained with Patient Plasma Samples*

\begin{tabular}{|c|c|c|c|c|}
\hline \multirow[b]{2}{*}{ Test } & \multirow[b]{2}{*}{ Sample tested } & \multicolumn{3}{|c|}{ Dates when patient samples were obtained } \\
\hline & & March 6 & March 28 & April 18 \\
\hline & & Clotting times (s) & Clotting times (s) & Clotting times (s) \\
\hline \multicolumn{5}{|c|}{ Coagulation tests } \\
\hline \multirow[t]{3}{*}{ PT } & 1:0 (patient:normal) & 148 & 102 & 96 \\
\hline & $1: 1$ & 96 & - & - \\
\hline & $0: 1$ (normal control) & 17 & 19 & 22 \\
\hline \multirow[t]{3}{*}{ APTT } & 1:0 (patient:normal) & 158 & 127 & - \\
\hline & $1: 1$ & 101 & - & - \\
\hline & $0: 1$ (normal control) & 35 & 44 & - \\
\hline \multirow[t]{2}{*}{ PNP $\ddagger$} & patient + platelets & 109 & 106 & - \\
\hline & patient + saline (control) & 131 & 117 & - \\
\hline \multirow[t]{3}{*}{ TT } & patient & 24 & 21 & - \\
\hline & normal & 20 & 20 & - \\
\hline & & \multicolumn{3}{|c|}{ Percent of mean normal value $\S$} \\
\hline \multicolumn{5}{|c|}{ Coagulation factor assays } \\
\hline \multirow[t]{2}{*}{ F II } & 10:90 (patient:substrate) & - & $21(76)^{\prime \prime}$ & - \\
\hline & $5: 95$ & - & 25 & - \\
\hline \multirow[t]{3}{*}{$\mathbf{F ~ V ~}$} & 10:90 (patient:substrate) & $\leq 1$ & $\leq 1(\leq 1)^{\prime \prime}$ & - \\
\hline & $5: 95$ & $\leq 1$ & $\leq 1$ & - \\
\hline & $1: 99$ & $\leq 1$ & - & - \\
\hline \multirow[t]{3}{*}{ F VII } & 10:90 (patient:substrate) & 4 & $52(100)^{\prime \prime}$ & - \\
\hline & $5: 95$ & 9 & 72 & - \\
\hline & $1: 99$ & 38 & - & - \\
\hline \multirow[t]{3}{*}{ F VIII } & 10:90 (patient:substrate) & $\leq 1$ & - & - \\
\hline & $5: 95$ & $\leq 1$ & - & - \\
\hline & $1: 99$ & 32 & - & - \\
\hline \multirow[t]{3}{*}{$\mathbf{F X}$} & 10:90 (patient:substrate) & 27 & $32(140)^{\prime \prime}$ & - \\
\hline & $5: 95$ & 32 & 50 & - \\
\hline & $1: 99$ & 60 & - & - \\
\hline
\end{tabular}

Abbreviations: PT, prothrombin time; APTT, activated partial thromboplastin time; PNP, platelet neutralization procedure; TT, thrombin time; F, Factor. * Tests and assays performed in the Special Coagulation Laboratory, Mayo Clinic. $¥$ Platelet neutralization procedure used to test for the presence of a "lupus anticoagulant," as described by Triplett et al. (52). § The range of normal values for coagulation factor assays is as follows: F II, 83-117\%; F V, 50-150\%; F VII, 65-135\%; F VIII, 55-145\%; F X, 45-155\%. " Results of coagulation factor assays performed on patient plasma samples after passage through a column of protein A-Sepharose to remove IgG. 
the patient plasma was added to an aliquot $(47.5 \mu \mathrm{l})$ of either normal or Factor V-deficient plasma. An aliquot (50 $\mu \mathrm{l})$ of 0.02 $\mathrm{M}$ Tris $\cdot \mathrm{HCl}, 0.15 \mathrm{M} \mathrm{NaCl}$ was then added, and incubation was carried out at $22^{\circ} \mathrm{C}$ for periods ranging from 30 to $300 \mathrm{~s}$. In samples with normal plasma, the incubation period was followed by the addition of thromboplastin $(50 \mu \mathrm{l})$ and $0.025 \mathrm{M} \mathrm{CaCl}_{2}$ $(50 \mu \mathrm{l})$ and the clotting time (prothrombin time) was determined at $37^{\circ} \mathrm{C}$. In samples incubated in Factor V-deficient plasma, an aliquot $(5 \mu \mathrm{l})$ of normal human plasma (as a source of Factor V) was added also, immediately followed by thromboplastin and $\mathrm{CaCl}_{2}$. With normal human plasma as substrate, the inhibitor, as evidenced by a prolongation of clotting time, was progressive, reaching a maximum value at $\sim 120 \mathrm{~s}$ of incubation. In Factor $\mathrm{V}$-deficient plasma as substrate, no progressive inhibition was apparent. These observations suggested that the inhibitor was directed against a component present in normal, but not Factor $\mathrm{V}$-deficient plasma, thus implicating Factor $\mathrm{V}$ as the inhibited component.

The specificity of the inhibitor was investigated by supplementing the patient plasma with purified bovine Factor $\mathrm{V}$ to levels ranging from 0 to $100 \mu \mathrm{g} / \mathrm{ml}$. (The Factor $V$ content of normal human plasma is typically $\sim 7 \mu \mathrm{g} / \mathrm{ml}$, [3].) For comparison, human Factor V-deficient plasma was similarly supplemented. After a period of incubation $(2 \mathrm{~min})$, the prothrombin times of the supplemented samples were determined. In the absence of bovine Factor V, the prothrombin times of both the patient plasma and the Factor V-deficient plasma samples were grossly prolonged at $\geq 120 \mathrm{~s}$. With increasing amounts of bovine Factor V, however, the prothrombin times of both specimens shortened to values near that of normal plasma. These observations indicated that the patient's inhibitor was specific for human Factor V (relative to bovine Factor V). In addition, because the patient's plasma would clot normally if supplemented with a suitable source of Factor V, the defect that yielded a prolonged prothrombin time in the absence of the supplement most likely was the inhibition of the endogenous Factor $\mathrm{V}$ of the sample.

An estimation of the quantity of the inhibitor present in the patient's plasma was determined by adding the patient's plasma in various volumes to a fixed volume of normal human plasma, and subsequently determining the prothrombin time of the mixture. The results of such an experiment are shown in Fig. 2.

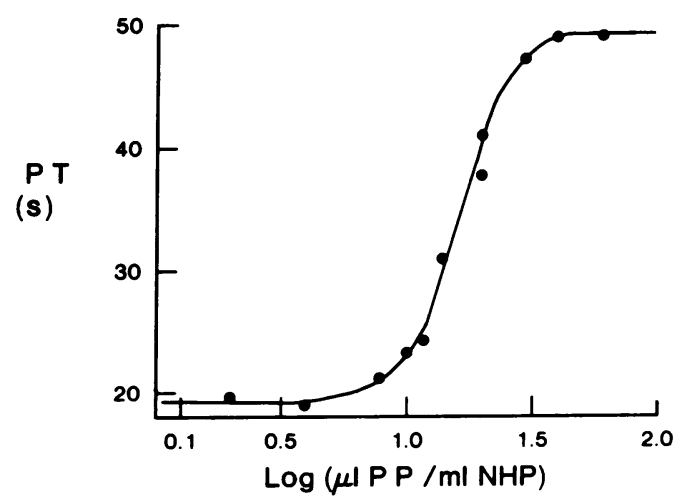

Figure 2. Prothrombin time $(P T)$ titration of the inhibitor in the patient's plasma $(P P)$ by mixing with normal human plasma $(N H P)$. Maximum inhibition of $P T$ occurs at a volume fraction (PP/NHP) of $\sim 0.035$ and half-maximum inhibition occurs at a volume fraction of $\sim 0.011$. The inhibitor titer (half-maximum inhibition) in the patient's plasma (28 March sample) is 1:89.
As the fraction of the test sample contributed by the patient plasma increased, the prothrombin time increased also, eventually reaching a plateau at $\sim 52 \mathrm{~s}$. This time is identical to that obtained when Factor V-deficient plasma (immunologically depleted) is reconstituted with Factor $\mathrm{V}$ at a level $0.6 \%$ of that found in normal plasma. Thus, the inhibitor appears to inhibit the activity of plasma Factor $\mathrm{V}$ in a thromboplastin-based assay to the extent of $\sim 99.4 \%$. The midpoint of the titration indicated in Fig. 2 corresponds to a volume fraction of $0.011 \mathrm{ml}$ of patient plasma/ml of normal plasma. Thus, at the time this sample was taken (28 March), the inhibitor content of $1 \mathrm{ml}$ of the patient's plasma was sufficient to neutralize the Factor $\mathrm{V}$ in $89 \mathrm{ml}$ of normal plasma, i.e., the titer was 89:1. A similar titration performed on a plasma sample obtained 18 April, 3 wk later, revealed a titer of $10: 1$, indicating a relatively transient existence of the inhibitor.

Isolation of the inhibitor by affinity chromatography. The inhibitor was isolated by affinity chromatography of the patient's plasma on protein A-Sepharose followed by human Factor VSepharose. Total protein $\left(A_{280 \mathrm{~nm}}\right)$ and inhibitor activity (clotting assay) were measured. Chromatography on protein A-Sepharose (not shown) quantitatively removed the inhibitor from the plasma sample. In addition, the plasma recovered by flowthrough from the protein A-Sepharose chromatography could be assayed for coagulation Factors II, V, VII, and X without interference (Table I). The clotting assays indicated that the plasma content of Factors II, VII, and X was normal after passage through protein A-Sepharose, whereas Factor V levels were $\leq 1 \%$ of normal. In addition to clotting assays, radioimmunometric analysis was performed for Factor V (3). The starting plasma level of Factor $\mathrm{V}$ antigen was $10 \mu \mathrm{g} / \mathrm{ml}$ before chromatography, and was $\leq 1 \mu \mathrm{g} / \mathrm{ml}$ afterwards. The immunologically detectable Factor $\mathrm{V}$ was found in the low pH eluate of the chromatography, indicating that it co-chromatographed with the inhibitor on protein A-Sepharose. When normal plasma was chromatographed on protein A-Sepharose, the Factor $\mathrm{V}$ of the sample was not retained by the column. Thus, the retention of Factor $V$ on the column after chromatography of the patient's plasma further suggests that the inhibitor is directed against Factor $V$. The yield of inhibitor upon chromatography on protein A-Sepharose was essentially quantitative (200 $\mathrm{U}$ applied, $190 \mathrm{U}$ recovered at pH 3.0).

Subsequent chromatography of the inhibitor on Factor VSepharose is indicated in Fig. 3. Upon application of the sample and continued washing at neutral $\mathrm{pH}$, some inhibitor activity was retarded, but not retained by the column. This was presumed to reflect an overloading phenomenon, but no efforts were made to confirm this by rechromatography. The vast majority of the protein of the sample was recovered in the application and wash of neutral $\mathrm{pH}(\mathrm{Z99 \% )}$ ), whereas the remainder of the protein $(\sim 1 \%)$ and an appreciable quantity of inhibitory activity was recovered upon elution at $\mathrm{pH} 2.8$. The two steps of chromatography provided a 131 -fold purification of the inhibitor, and $\sim 130$ $\mu \mathrm{g}$ protein from $2 \mathrm{ml}$ of plasma. The overall yield was $17 \%$. The relatively poor yield was due in part to the apparent limited capacity of the Factor V-Sepharose column.

Analysis of the inhibitor by gel electrophoresis. Samples obtained upon elution at low $\mathrm{pH}$ from protein A-Sepharose and human Factor V-Sepharose are shown in Fig. 4. The sample obtained after protein A-Sepharose chromatography had electrophoretic mobility typical of plasma IgG, migrating with apparent molecular weight of 150,000 (nonreduced sample) and 


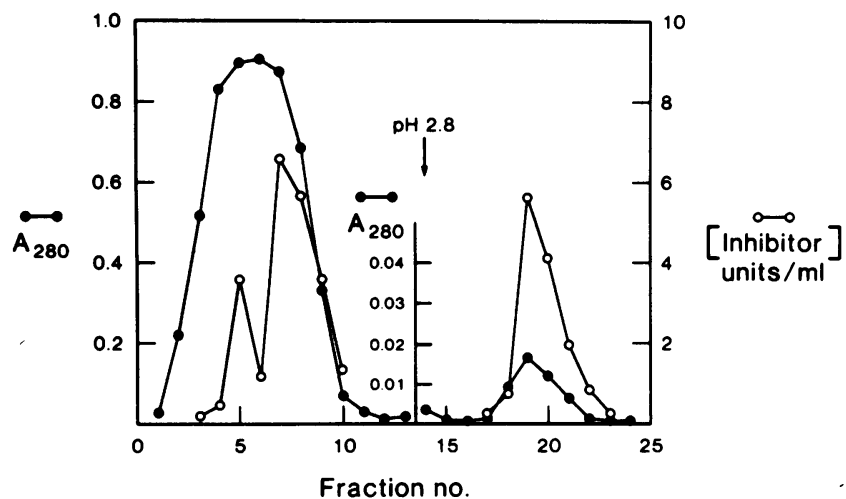

Figure 3. Chromatography of the patient's IgG on human Factor V-Sepharose. The majority ( $299 \%$ ) of the patient's IgG (purified by preceding chromatography on protein A-Sepharose, 28 March plasma sample) is not retained on Factor V-Sepharose, whereas IgG greatly enriched in inhibitor activity is eluted from Factor V-Sepharose at pH 2.8.

with heavy and light chain of respective apparent molecular weights of 50,000 and 25,000 (reduced sample). The sample obtained after additional chromatography on Factor V-Sepharose also electrophoresed as an IgG.

Studies of the inhibition of the Factor Va activity of prothrombinase assembled on platelets or phospholipid vesicles. The inhibition of prothrombinase activity in systems employing purified components was studied. Prothrombinase consisted of $\mathrm{Ca}^{2+}$, Factor $\mathrm{Xa}(10 \mathrm{nM})$, and Factor $\mathrm{Va}(1.0 \mathrm{nM})$ and lipid (phosphatidylcholine-phosphatidylserine) vesicles, or platelets in place of Factor $\mathrm{V}(\mathrm{Va})$ and phospholipid. Initial rates of thrombin formation were measured in the presence of the isolated IgG
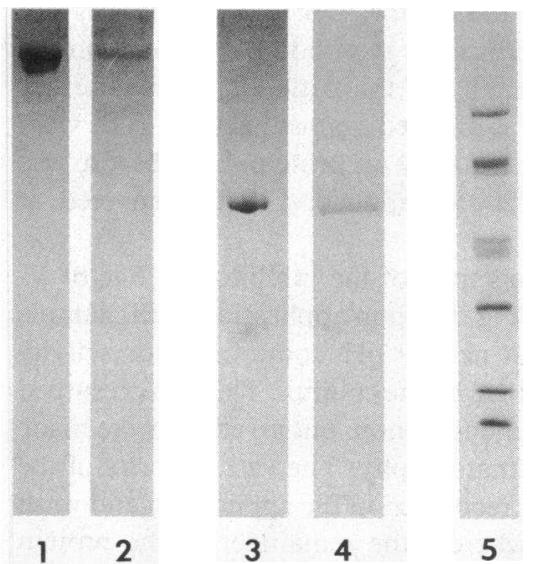

Figure 4. Sodium dodecyl sulfate-polyacrylamide slab gel (5-15\% linear acrylamide gradient) electrophoretogram of the patient's IgG isolated by protein A-Sepharose chromatography, and of the Factor V-inhibitor fraction of the patient's IgG isolated by Factor V-Sepharose chromatography (Coomassie blue staining). Lanes 1 and 2: nonreduced proteins. Lanes 3-5: reduced proteins. Lanes 1 and 3: patient's IgG (protein A-Sepharose eluate, pH 3.0). Lanes 2 and 4: patient's Factor V inhibitor (Factor V-Sepharose eluate, pH 2.8). Lane 5: protein molecular weight standards (from top to bottom: 94,000 , phosphorylase $B ; 67,000$, bovine serum albumin; 43,000 , ovalbumin; 30,000 , carbonic anhydrase; 20,100 , soybean trypsin inhibitor; 14,400 , $\alpha$-lactalbumin). fraction from the patient's plasma (protein A-Sepharose) at various concentrations. The results are shown in Fig. 5. Inhibition occurred whether prothrombinase was assembled on platelets or phospholipid vesicles. In either case, the phenomenon exhibited saturation with respect to inhibitor levels. The extent of inhibition obtained at saturation differed substantially in the two systems. With the vesicles plus Factor $\mathrm{Va}$, inhibition was nearly complete ( $295 \%)$; whereas with platelets, the extent of inhibition at saturation was only $\sim 50 \%$. No obvious explanation for this differential effect is available.

Studies of the accessibility of platelet Factor $V$ to the inhibitor. The IgG fraction isolated from normal or patient plasma was added to whole blood. After 1 or $8 \mathrm{~h}$ of incubation at $37^{\circ} \mathrm{C}$, platelets were isolated from the blood and their capacity to support prothrombin activation in the presence of added Factor $\mathrm{Xa}$ was studied. In both instances, prothrombinase activity was determined before and after stimulation of the platelets with thrombin. The time course of thrombin generation of platelets, recovered from blood incubated for $8 \mathrm{~h}$ with normal or patient $\mathrm{IgG}$, is shown in Fig. 6. The reaction profiles are essentially indistinguishable, indicating that the Factor $\mathrm{V}$ activity of the two sets of platelets was essentially intact, which in turn suggests that the platelet Factor $V$ was not accessible to the inhibitor during the course of incubation of the inhibitor and whole blood. The plasmas recovered from the two samples clearly indicated the presence of the inhibitor as the prothrombin time of the sample incubated with control IgG was normal at $17.8 \mathrm{~s}$, whereas that of the sample incubated with the patient's IgG was grossly prolonged at $76.8 \mathrm{~s}$. The only values that distinguish the two

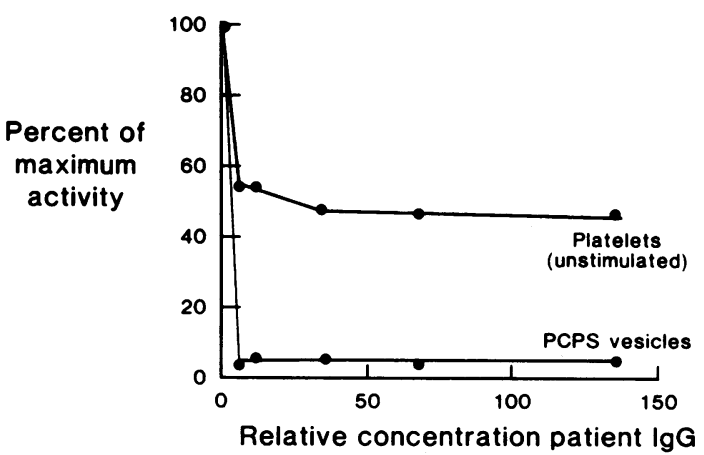

Figure 5. Influence of the patient's IgG on the Factor Va activity of prothrombinase assembled on normal platelets or on phospholipid (phosphatidylcholine-phosphatidylserine, $P C P S$ ) vesicles. Prothrombinase activity (initial rate) was quantitated fluorometrically in a system containing purified components (prothrombin, Factor $\mathrm{Xa}$ ), calcium ion, and the fluorescent thrombin inhibitor, DAPA; and which also contained varying quantities of the patient's IgG (protein A-Sepharose) and either PCPS vesicles and Factor Va, or washed normal unstimulated platelets. The prothrombinase activity of the IgG-containing mixtures is expressed as a percentage of the activity observed in the absence of the patient's IgG. The concentration of IgG in the assay mixtures is expressed relative to the IgG content of the patient's plasma (28 March sample); i.e., 100 represents an amount of IgG equivalent to that present in the patient's undiluted plasma. The patient's IgG, at a concentration $\leq 10 \%$ of that present in his plasma, causes near total ( $\geq 95 \%)$ inhibition of prothrombinase assembled on PCPS vesicles. At saturating levels, the patient's IgG causes less than total inhibition ( $\sim 50 \%$ inhibition) of prothrombinase assembled on normal platelets. In the latter experiment, the platelets are the only source of Factor $\mathrm{V} / \mathrm{Va}$ in the test system. 


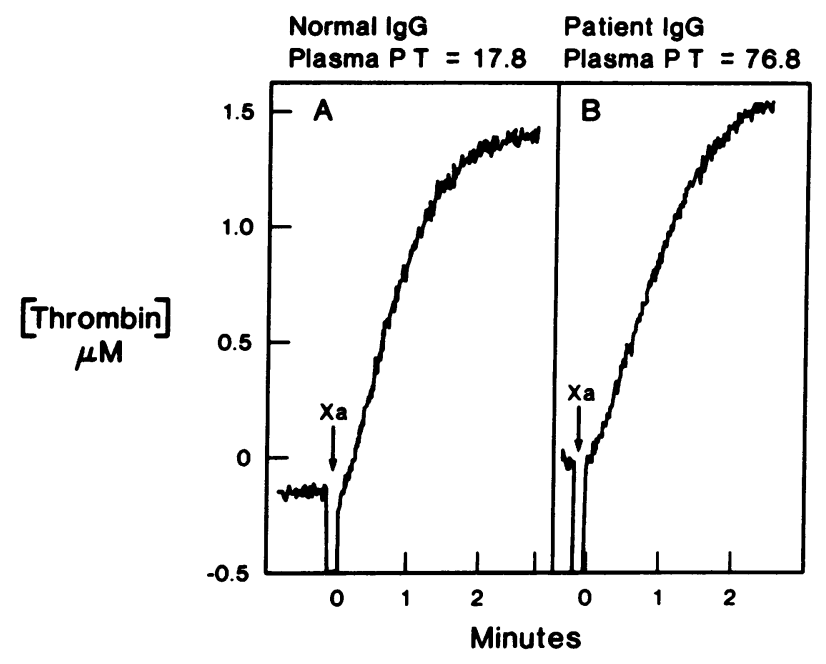

Figure 6. Influence of normal $(A)$ or patient $(B) \mathrm{IgG}$ on the capability of normal platelets, isolated from whole blood supplemented with IgG for $\mathbf{8 h}$, to support prothrombinase activity in the absence of exogenous Factor V/Va. Equivalent amounts of normal IgG or patient IgG (from 18 April plasma specimen), isolated by affinity chromatography on protein A-Sepharose, were incubated with normal whole blood $\left(37^{\circ} \mathrm{C}, 8 \mathrm{~h}\right)$ after which the platelets were isolated, washed, and thrombin-stimulated $(1.0 \mathrm{U} / \mathrm{ml}, 2 \mathrm{~min})$. Prothrombinase activity was quantitated by fluorometric determination of the rate of thrombin formation after initiation of the reaction with enzyme $(\mathrm{Xa})$ added to a mixture containing platelets, prothrombin, DAPA, and $\mathrm{Ca}^{2+}$. Although the Factor $\mathrm{V}$ activity of the plasma from blood supplemented with patient IgG $(B)$ was markedly inhibited (plasma prothrombin time (PT) $=76.8 \mathrm{~s}$; control plasma $P T=17.8 \mathrm{~s}$ ), platelets isolated from inhibitor-supplemented blood $(B)$ were indistinguishable from platelets isolated from the same blood supplemented with allogeneic $\operatorname{Ig} G(A)$ with respect to their capability to support platelet Factor $\mathrm{V} / \mathrm{Va}$-dependent prothrombinase activity.

groups of platelets were those obtained before stimulation of the platelets. Those platelets incubated with the patient's IgG were consistently less active before thrombin stimulation than those incubated with normal IgG. Both groups of platelets yielded similar activity after stimulation, however. These data imply that the inhibitor may have functioned to prevent partial, adventitious activation of the platelets during the prolonged incubation. The results of these studies are summarized in Table II.

\section{Discussion}

The results of the present study indicate that this patient's Factor $\mathrm{V}$ inhibitor is an IgG antibody. The antibody was acutely acquired in association with drug treatment (including the aminoglycoside antibiotic, gentamicin) of a patient who had disseminated malignancy. At the times of initial blood sampling, the titer of the antibody exceeded the Factor $\mathrm{V}$ level of normal plasma by a factor of 100.3 wk after initial chemotherapy, the antibody titer exceeded plasma Factor $\mathrm{V}$ levels by 10 -fold. In spite of the relatively high titer of inhibition and profound inhibition of plasma Factor V, the patient displayed no bleeding tendencies even upon surgical challenge. The antibody profoundly inhibited Factor $\mathrm{V}$ either in plasma or in a system of purified components ( $295 \%$ inhibition). In addition, the inhibitor appears specific for human Factor V. The antibody also
Table II. Summary of the Prothrombinase Activity of Platelets Isolated after Incubation of Whole Blood with Normal or Factor V-Inhibitor IgG

\begin{tabular}{lll}
\hline & \multicolumn{2}{l}{ Platelet prothrombinase activity* } \\
\cline { 2 - 3 } Sample & $\begin{array}{l}\text { Unstimulated } \\
\text { platelets }\end{array}$ & $\begin{array}{l}\text { Thrombin-stimulated } \\
\text { platelets }\end{array}$ \\
\hline $\begin{array}{l}\text { Incubation 1 h, } 37^{\circ} \mathrm{C} \\
\text { Blood + Normal IgG }\end{array}$ & 4.20 & \\
Blood + Patient IgG & 2.38 & 4.93 \\
Incubation 8 h, 37 & & 5.81 \\
Blood + Normal IgG & & \\
Blood + Patient IgG & 3.59 & 7.09 \\
& 1.49 & 5.50 \\
\hline
\end{tabular}

* Rate of prothrombin conversion to thrombin $\left[\left(\mathrm{mol} \cdot \mathrm{1}^{-1} \cdot \mathrm{s}^{-1} / 10^{8}\right.\right.$ platelets) $\times 10^{9}$ ], determined fluorometrically.

inhibited platelet prothrombinase activity (Factor $\mathrm{V}$ ) to a limited extent ( $\sim 50 \%$ at saturation). Although the antibody would inhibit platelet prothrombinase activity when the reaction occurred in vitro in the presence of the antibody, platelets in whole blood exposed to the antibody for $8 \mathrm{~h}$ behaved normally when isolated and washed. This observation suggested that the Factor $\mathrm{V}$ of unstimulated platelets was not accessible to the inhibitor. The apparent inaccessibility of Factor $\mathbf{V}$ in unstimulated washed platelets to a Factor $\mathrm{V}$ inhibitor was previously observed by Miletich et al. (9). They reported that prothrombinase activity, expressed in vitro by thrombin-stimulated washed platelets, could be inhibited in the presence of the antibody $(9,42)$. Inhibition occurred only when platelets were activated and preincubated with the inhibitor.

Table III summarizes features of 27 cases of Factor $\mathbf{V}$ inhibitors reported to date. These inhibitors generally have arisen in otherwise hemostatically normal individuals, with the exception of one patient with congenital Factor $\mathrm{V}$ deficiency who developed a transient Factor $V$ inhibitor in association with blood transfusion (18). Factor $\mathrm{V}$ inhibitors have arisen in association with recent surgical operations, blood transfusions, tuberculous infections, and/or administration of aminoglycoside antibiotics (e.g., streptomycin, gentamicin, or kanamycin). In all instances in which the inhibitors were characterized, they have been IgG antibodies. Further characterization in two instances has elucidated antibodies of $\mathrm{IgG}_{4}$ subclass, and in one case monoclonality was asserted (53). It is of interest that acquired inhibitors of Factor VIII, a coagulation protein structurally and functionally homologous with Factor V (54), have frequently been of $\mathrm{IgG}_{4}$ subclass $(40,55)$. Characteristically, the existence of anti-Factor $\mathrm{V}$ antibodies has been transient. In some instances human Factor $\mathrm{V}$ inhibitors have been found to be inactive toward Factor $\mathrm{V}$ of other mammals. In the majority of the cases, some bleeding tendency has been observed, but only occasionally has the bleeding tendency proven fatal. In some cases, including the present one, no abnormal bleeding has been observed, despite surgical challenge in the presence of total or nearly total inhibition of plasma Factor $\mathrm{V}$ activity. Generally, the estimated antibody titer correlates with the occurrence of bleeding and its severity (Table IV).

Current concepts of hemostasis suggest that Factor $\mathrm{V}$ is essential for normal hemostasis. These concepts are apparently 


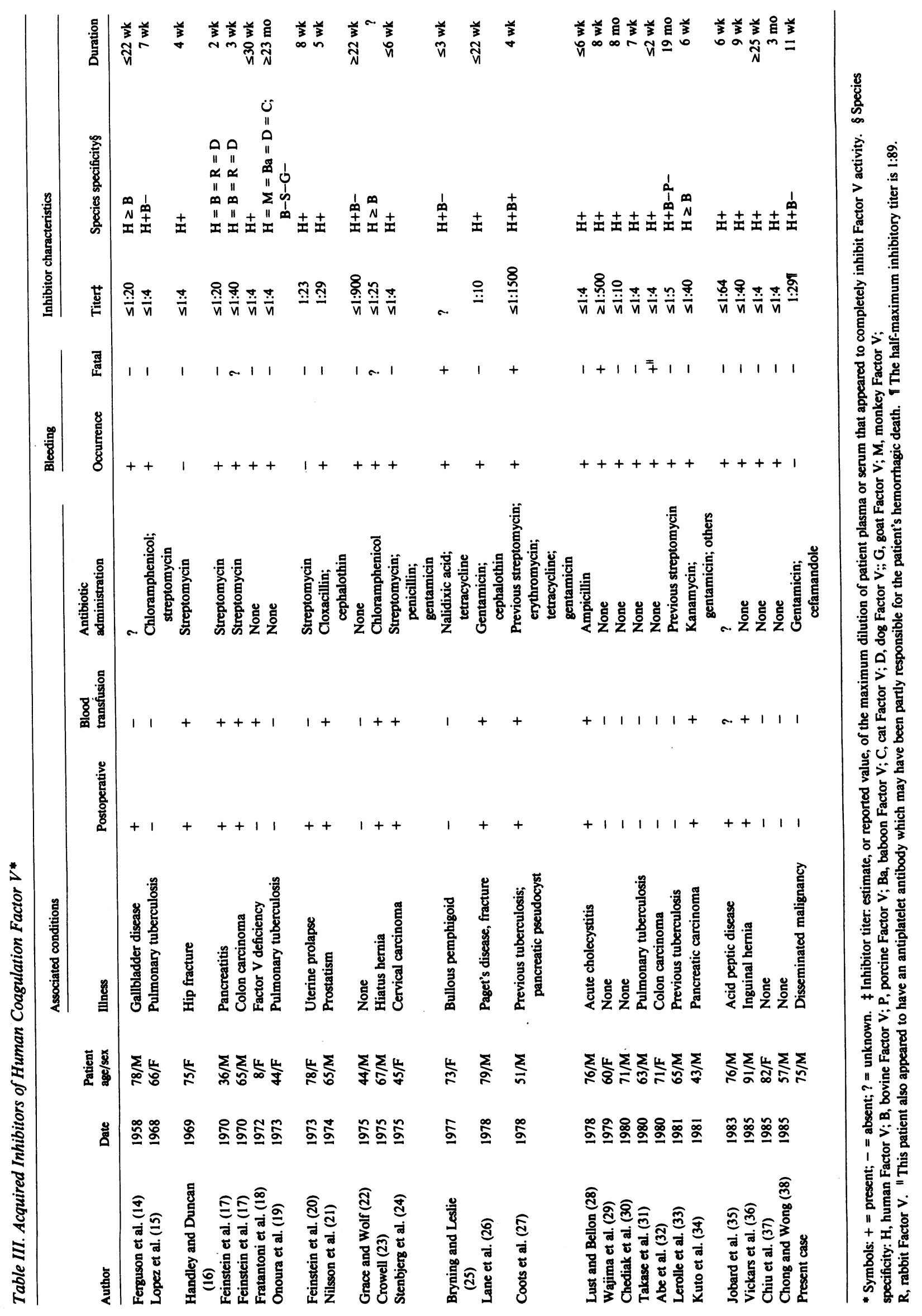


Table IV. Relationship between Factor $V$

Inhibitor Titer and Clinical Bleeding

\begin{tabular}{lcl}
\hline Clinical bleeding & Number of cases & Mean inhibitor titer* \\
\hline None & 3 & $1: 19$ \\
Present, not fatal & 20 & $1: 62$ \\
Present, fatal & 4 & $1: 668$ \\
Total & 27 & \\
\hline
\end{tabular}

* Mean of the estimates of reported values (Table III) of the maximum dilution of patient plasma or serum that appeared to completely inhibit Factor V activity.

challenged by the frequent, but not universal, failure to observe major bleeding complications in patients with acquired Factor $\mathrm{V}$ inhibitors. The current work, plus recent observations that help differentiate the functional significance of platelet and plasma pools of Factor V, may help reconcile the apparent discrepancy between the presumed significance of Factor $\mathrm{V}$ in hemostasis and the clinically observed paucity of severe or fatal bleeding problems associated with Factor $\mathrm{V}$ inhibitors. Tracy et al. (44) studied a family whose affected members displayed profound bleeding tendencies in association with relatively normal pools of plasma Factor V, but functionally defective platelet Factor V. These studies specifically imply a role for platelet Factor $\mathrm{V}$ in normal hemostasis. The current studies suggest that platelet Factor $\mathrm{V}$ is relatively "protected" from an anti-Factor $\mathrm{V}$ antibody in whole blood, even though plasma Factor $\mathrm{V}$ is completely neutralized. Thus, within the confines of these examples, bleeding difficulties can be associated with congenitally defective platelet Factor $\mathrm{V}$ in the presence of normal plasma Factor V; and conversely, no apparent bleeding difficulties are observed despite inhibited plasma Factor V, so long as platelet Factor $\mathrm{V}$ is relatively inaccessible to a Factor $\mathrm{V}$ inhibitor. Previous studies by Miletich et al. (42) also specifically implicate platelet Factor $\mathrm{V}$ in normal hemostasis in that, among several patients with congenital Factor $\mathrm{V}$ deficiencies, those with profoundly deficient Factor Xa binding to platelets bleed severely, whereas those with mild deficiencies in binding do not bleed severely. Because Factor Xa binding is (platelet) Factor Va-dependent (8), normal platelet-Xa binding suggests normal platelet Va expression.

Platelets contain $\sim 20 \%$ of the Factor $\mathrm{V}$ of human blood and comprise $\sim 0.16 \%$ of the volume of human blood. Therefore, the nominal Factor $\mathrm{V}$ concentration of platelets exceeds that of plasma by an approximate factor of 100 (Fig. 7). Thus, in a situation involving a local accumulation of platelets with an appreciable exclusion of plasma, a "rapid" release or exposure of Factor $\mathrm{V}$ which, up to the point of exposure, had been protected from the antibody, might create sufficiently high local concentrations of Factor $\mathrm{V}$ to overwhelm an inhibitor, even though its titer was high relative to plasma levels of Factor V. The patient studied here had a Factor $\mathrm{V}$ inhibitor titer of approximately 100 and did not bleed; a patient with a titer of approximately 1,500 , however, experienced hemorrhagic difficulties that proved fatal (27).

The lack of tendencies to bleed in the presence of Factor $\mathrm{V}$ inhibitors with titers substantially exceeding plasma Factor $\mathrm{V}$ levels may be reconciled through considerations of the relative

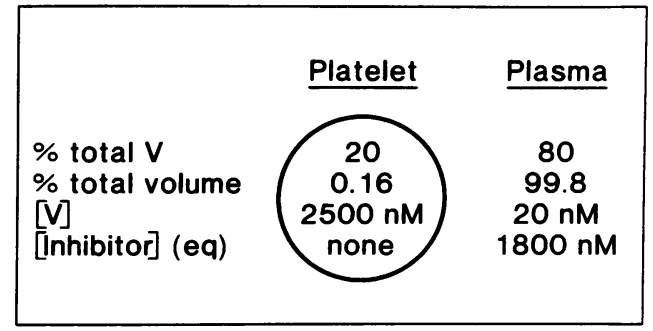

Figure 7. Depiction of the relative concentrations of Factor $\mathrm{V}(V)$ and of Factor $\mathrm{V}$ inhibitor (Inhibitor) in the two major pools present in the patient's whole blood. Although the platelet pool contains only $20 \%$ and the plasma pool contains $80 \%$ of the Factor V present in whole blood, because of the small volume of the platelets, relative to the plasma volume, the formal Factor $\mathrm{V}$ concentration of platelets exceeds that of plasma by $>100$-fold. A plasma Factor V inhibitor IgG, capable in the present case of neutralizing the Factor $\mathrm{V}$ activity in 90 equivalent (eq) volumes of plasma, was relatively inaccessible to the Factor $\mathrm{V}$ present in the platelet pool. Under hemostatic conditions in which platelets might accumulate, it is hypothesized that the "local" concentration of functional Factor $\mathrm{V}$ delivered by an accumulating platelet mass, together with the relative local exclusion of inhibitor in plasma, may be sufficient to achieve satisfactory hemostasis despite the nearly total inhibition of plasma Factor V activity.

inaccessibility of platelet Factor $\mathrm{V}$ to the inhibitor, and the concentration of platelet Factor $\mathrm{V}$ relative to that of plasma Factor V. These concepts are suggested by Fig. 7. Two pools of Factor $\mathrm{V}$ are depicted, one in platelets, the other in plasma. Although the platelets contain only $20 \%$ of the total Factor V of whole blood, they comprise such a relatively small volume that their formal concentration of Factor $\mathrm{V}$ exceeds that of plasma by $>100$-fold. The inhibitor level present in this patient's whole blood was sufficient to neutralize 90 times the Factor $\mathrm{V}$ content of whole blood (including platelets). Platelet Factor V, however, appeared relatively inaccessible to this inhibitor in whole blood. Thus, under conditions in which platelets might accumulate, as in hemostatic plug formation, plasma (and inhibitor) might be largely excluded. If the platelets then were to release or expose their Factor V, the "local" concentration (and therefore the amount) of Factor $V$ expressed might be sufficient to overwhelm the inhibitor locally. A phenomenon such as this would account for the lack of bleeding under circumstances where plasma Factor $\mathrm{V}$ is completely neutralized by a relatively high-titer antibody whereas platelet Factor $\mathrm{V}$ remains intact.

\section{Acknowledgments}

The authors wish to thank Dr. Paula B. Tracy for helpful discussions; Ms. Lisa L. Eide, Mr. Scott E. Kaese, and Mr. Hugh Hoogendorn for assistance with experimental procedures; Dr. Robert A. Kyle for immunoelectrophoretic analysis of the patient's serum; Dr. Peter M. Banks for special studies and review of the patient's tissue biopsy specimens; Dr. Yoshihiko Sawada for interpretation of Japanese scientific literature; and Ms. Marilyn Parker, Ms. Sandra Schumann, and Ms. Dorothy Suddendorf for secretarial assistance.

This work was supported by grants HL-30365 to Dr. Nesheim, HL-16150 to Dr. Mann, and HL-17430 to Drs. Mann and Bowie from the National Institutes of Health; by grants DG309 and DG310 (to Dr. Nesheim) from the Medical Research Council of Canada; by a Rappaport Clinician Investigator Award to Dr. Nichols; and by the Mayo Foundation. 


\section{References}

1. Katzmann, J. A., M. E. Nesheim, L. S. Hibbard, and K. G. Mann. 1981. Isolation of functional human coagulation factor $\mathrm{V}$ by using a hybridoma antibody. Proc. Natl. Acad. Sci. USA. 78:162-166.

2. Nesheim, M. E., J. A. Katzmann, P. B. Tracy, and K. G. Mann. 1981. Factor V. Methods Enzymol. 80:249-274.

3. Tracy, P. B., L. L. Eide, E. J. W. Bowie, and K. G. Mann. 1982. Radioimmunoassay of factor $\mathrm{V}$ in human plasma and platelets. Blood. 60:59-63.

4. Mann, K. G. 1976. Prothrombin. Methods Enzymol. 45:123-146.

5. Davie, E. W., and K. Fujikawa. 1975. Basic mechanisms of blood coagulation. Annu. Rev. Biochem. 44:799-829.

6. Nesheim, M. E. 1984. Quantitative features of the structure, functions and modulation of prothrombinase. Surv. Synth. Pathol. Res. 3:219-232.

7. Nesheim, M. E., J. B. Taswell, and K. G. Mann. 1979. The contribution of factor $\mathrm{V}$ and factor $\mathrm{Va}$ to the activity of prothrombinase. $J$. Biol. Chem. 254:10952-10962.

8. Tracy, P. B., M. E. Nesheim, and K. G. Mann. 1981. Coordinate binding of factor $\mathrm{Va}$ and factor $\mathrm{Xa}$ to the unstimulated platelet. J. Biol. Chem. 256:743-751.

9. Miletich, J. P., C. M. Jackson, and P. W. Majerus. 1978. Properties of the factor Xa binding site on human platelets. J. Biol. Chem. 253: 6908-6916.

10. Nesheim, M. E., C. Kettner, E. Shaw, and K. G. Mann. 1981. Cofactor dependence of the incorporation of factor $\mathrm{Xa}$ into the prothrombinase complex. J. Biol. Chem. 256:6537-6540.

11. Nesheim, M. E., S. Eid, and K. G. Mann. 1981. Assembly of the prothrombinase complex in the absence of prothrombin. J. Biol. Chem. 256:9874-9882.

12. Nesheim, M. E., R. P. Tracy, and K. G. Mann. 1984. "Clotspeed," a mathematical simulation of the functional properties of prothrombinase. J. Biol. Chem. 259:1447-1453.

13. Owren, P. A. 1947. The coagulation of blood: Investigations of a new clotting factor. Acta Med. Scand. [Suppl.] 194:1-327.

14. Ferguson, J. H., C. L. Johnston, Jr., and D. A. Howell. 1958. A circulating inhibitor (anti-AcG) specific for the labile factor-V of the blood clotting mechanism. Blood. 13:382-397.

15. Lopez, V. R., R. Pflugshaupt, and R. Bütler. 1968. A specific inhibitor of human clotting factor V. Acta Haematol. (Basel). 40:275285.

16. Handley, D. A., and E. M. Duncan. 1969. A circulating anticoagulant specific for factor V. Pathology. 1:265-272.

17. Feinstein, D. I., S. I. Rapaport, W. G. McGehee, and M. J. Patch. 1970. Factor $\mathrm{V}$ anticoagulants: clinical, biochemical and immunological observations. J. Clin. Invest. 49:1578-1588.

18. Fratantoni, J. C., M. Hilgartner, and R. L. Nachman. 1972. Nature of the defect in factor $\mathrm{V}$ deficiency: study in a patient with an acquired circulating anticoagulant. Blood. 39:751-758.

19. Onoura, C. A., J. Lindenbaum, and H. L. Nossel. 1973. Massive hemorrhage associated with circulating antibodies to factor V. Am. J. Med. Sci. 265:407-417.

20. Feinstein, D. I., S. I. Rapaport, and M. M. Y. Chong. 1973. Factor $\mathrm{V}$ inhibitor: report of a case, with comments on a possible effect of streptomycin. Ann. Intern. Med. 78:385-388.

21. Nilsson, I. M., V. Hedner, M. Ekberg, and T. Dennenberg. 1974. Circulating anticoagulant against factor V. Acta Med. Scand. 195:7377.

22. Grace, C. S., and P. Wolf. 1975. A high titre circulating inhibitor of human factor V: clinical biochemical and immunological features and its treatment by plasmapheresis. Thromb. Diath. Haemorrh. 34:322. (Abstr.)

23. Crowell, E. B. 1975. Observations on a factor-V inhibitor. Br. J. Haematol. 29:397-404.

24. Stenbjerg, S., S. Husted, and K. Mygind. 1975. A circulating factor V inhibitor: possible side effect of treatment with streptomycin. Scand. J. Haematol. 14:280-285.
25. Bryning, K., and J. Leslie. 1977. Factor V inhibitor and bullous pemphigoid. Br. Med. J. 2:677-678.

26. Lane, T. A., S. S. Shapiro, and E. R. Burke. 1978. Factor V antibody and disseminated intravascular coagulation. Ann. Intern. Med. 89:182-185

27. Coots, M. C., A. F. Muhleman, and H. I. Glueck. 1978. Hemorrhagic death associated with a high titer factor $\mathrm{V}$ inhibitor. Am. J. Hematol. 4:193-206.

28. Lust, A., and A. Bellon. 1978. A circulating anticoagulant against factor V. Acta Clin. Belg. 33:62-65.

29. Wajima, T., D. A. Schenk, and T. R. Maloney. 1979. Severe bleeding associated with a circulating anticoagulant to factor V. Blood. 54(Suppl. 1):308a. (Abstr.)

30. Chediak, J., J. B. Ashenhurst, I. Gorlick, and R. K. Desser. 1980. Successful management of bleeding in a patient with factor $\mathrm{V}$ inhibitor by platelet transfusions. Blood. 56:835-841.

31. Takase, T., Y. Fujimura, S. Mikami, H. Fukui, H. Fukui, and A. Hashimoto. 1980. Factor V inhibitor developed in a patient with pulmonary tuberculosis (author's translation). Rinsho Ketsueki. 21:10381046.

32. Abe, T., M. Kazama, K. Itukazu, T. Kinoshita, T. Ogushi, C. Tahara, and H. Fukui. 1980. A case of sigmoid cancer who acquired factor V inhibitor producibility and treated with factor VIII inhibitor bypassing activity preparation FEIBA-with bibliographic review (author's translation). Rinsho Ketsueki. 21:1664-1673.

33. Lerolle, D., C. Dreyer-Dufer, and J. P. Allain. 1981. Anticoagulant circulant spécifique du facteur V. Nouv. Presse Méd. 10:1483-1487.

34. Kuto, M., Y. Izuchi, K. Degushi, T. Morito, C. Lee, and H. Wada. 1981. An inhibitor against factor $\mathrm{V}$ occurring postoperatively in a case of pancreatic cancer. Nippon Ketsueki Gakkai Zasshi. 44:938950.

35. Jobard, J., N. Pourcher, N. Gratecos, and J. Bayle. 1983. Syndrome hémorragique du à un anticoagulant circulant antifacteur V. Presse Méd. 12:1606.

36. Vickars, L. M., R. W. Coupland, and S. C. Naiman. 1985. The response of an acquired factor $\mathrm{V}$ inhibitor to activated factor IX concentrate. Transfusion. 25:51-63.

37. Chiu, H. C., A. K. Rao, C. Beckett, and R. W. Colman. 1985 Immune complexes containing factor $\mathrm{V}$ in a patient with an acquired neutralizing antibody. Blood. 65:810-818.

38. Chong, L.-L., and Y.-C. Wong. 1985. A case of factor V inhibitor. Am. J. Hematol. 19:395-399.

39. Feinstein, D. A., and S. I. Rapaport. 1972. Acquired inhibitors of blood coagulation. 1972. In Hemostasis and Thrombosis, Vol. I T. H. Spaet, editor. Grune \& Stratton, New York. 75-95.

40. Shapiro, S. S., and M. Hultin. 1975. Acquired inhibitors to blood coagulation factors. Sem. Thromb. Hemostasis. 1:336-385.

41. Feinstein, D. I. 1978. Acquired inhibitors of factor V. Thromb. Haemostasis. 39:663-674.

42. Miletich, J. P., D. W. Majerus, and P. W. Majerus. 1978. Patients with congenital factor $\mathrm{V}$ deficiency have decreased factor $\mathrm{Xa}$ binding sites on their platelets. J. Clin. Invest. 62:824-831.

43. Roberts, H. R., and K. D. Zeitler. 1982. Inherited disorders of prothrombin conversion. In Hemostasis and Thrombosis. R. W. Colman, J. Hirsh, V. J. Marder, and E. W. Salzman, editors. J. B. Lippincott, Philadelphia. 127-144.

44. Tracy, P. B., A. R. Giles, K. G. Mann, L. L. Eide, H. Hoogendoorn, and G. Rivard. 1984. Factor V (Quebec): a bleeding diathesis associated with a qualitative platelet factor V deficiency. J. Clin. Invest. $74: 1221-1226$

45. Borchgrevink, C. F., and P. A. Owren. 1961. The hemostatic effect of normal platelets in hemophilia and factor $\mathrm{V}$ deficiency. Acta Med. Scand. 170:375-383.

46. Bajaj, S. P., S. I. Rapaport, and C. Prodanos. 1981. A simplified procedure for purification of human prothrombin, factor IX and factor X. Prep. Biochem. 11:397-412.

47. Barenholz, Y., D. Gibbs, B. J. Litman, J. Goll, T. E. Thompson, 
and F. D. Carlson. 1977. A simple method for the preparation of homogeneous phospholipid vesicles. Biochemistry. 16:2806-2810.

48. Nesheim, M. E., F. G. Prendergast, and K. G. Mann. 1979. Interactions of a fluorescent active-site-directed inhibitor of thrombin: dansylarginine N-(3-ethyl-1,5-pentanediyl)amide. Biochemistry. 18:9961003.

49. Bowie, E. J. W., J. H. Thompson, Jr., P. Didisheim, and C. A. Owen, Jr. 1971. Assays of coagulation factors. In Mayo Clinic Laboratory Manual of Hemostasis. W. B. Saunders Co., Philadelphia. 97-114.

50. Neville, D. M., Jr. 1971. Molecular weight determination of protein-dodecyl sulfate complexes by gel electrophoresis in a discontinuous buffer system. J. Biol. Chem. 246:6328-6334.

51. Mustard, J. F., D. W. Perry, N. G. Ardlie, and M. A. Packham. 1972. Preparation of suspensions of washed platelets from humans. $B$ r. J. Haematol. 22:193-204.
52. Triplett, D. A., J. T. Brandt, D. Kaczor, and J. Schaeffer. 1983 Laboratory diagnosis of lupus inhibitors: a comparison of the tissue thromboplastin inhibition procedure with a new platelet neutralization procedure. Am. J. Clin. Pathol. 79:678-682.

53. Hurtubise, P. E., M. C. Coots, D. J. Jacob, A. F. Muhleman, and H. I. Glueck. 1979. A monoclonal $\operatorname{IgG}_{4}(\lambda)$ with factor $\mathrm{V}$ inhibitory activity. J. Immunol. 122:2119-2121.

54. Church, W. R., R. L. Jernigan, J. Toole, R. M. Hewick, J. Knopf, G. J. Knutson, M. E. Nesheim, K. G. Mann, and D. N. Fass. 1984. Coagulation factors $\mathrm{V}$ and VIII and ceruloplasmin constitute a family of structurally related proteins. Proc. Natl. Acad. Sci. USA. 81:69346937.

55. Hoyer, L. W., M. S. Gawryl, and B. de la Fuente. 1984. Immunochemical characterization of factor VIII inhibitors. Prog. Clin. Biol. Res. 150:73-85. 